\title{
Convergências e similaridades entre os campos da educação ambiental, educação estética e educação patrimonial
}

Neste artigo de revisão teórica, evidencia-se uma conjuntura de crises e transições paradigmáticas, desafiando o mundo contemporâneo a trilhar os caminhos que levem à construção de sociedades sustentáveis. Pela pesquisa bibliográfica, procurou-se estabelecer um diálogo entre a Educação Ambiental, Estética e Patrimonial, em busca de suas convergências e similaridades.

Palavras-chave: Crises Epistemológicas; Educação Ambiental; Educação Patrimonial; Educação Estética.

\section{Convergences and similarities between the fields of environmental education, aesthetic education and heritage education}

\begin{tabular}{l} 
In this article of theoretical revision, it is evident a conjuncture of crises and paradigmatic transitions, challenging the contemporary world to \\
follow the paths that lead to the construction of sustainable societies. Through the bibliographical research, we tried to establish a dialogue \\
between Environmental, Aesthetic and Patrimonial Education, in search of their convergences and similarities. \\
\hline Keywords: Epistemological Crises; Environmental Education; Patrimonial Education; Aesthetic Education.
\end{tabular}

Topic: Educação Ambiental

Reviewed anonymously in the process of blind peer
Received: 18/03/2017

Approved: 17/05/2017
José Matarezi

Universidade da Região de Joinville, Brasil http://lattes.cnpq.br/3554616369612517 jmatarezi@univali.br

Paulo Ivo Koehntopp

Instituição, País.

http://lattes.cnpq.br/4323476442404137

pauloik@uol.com.br

Nadja de Carvalho Lamas

Universidade Federal do Rio Grande do Sul, Brasil

http://lattes.cnpq.br/9001798665217438

nadja.carvalho@univille.br d

DOI: 10.6008/SPC2179-6858.2017.003.0020
Referencing this:

MATAREZI, J.; KOEHNTOPP, P. I.; LAMAS, N. C.. Convergências e similaridades entre os campos da educação ambiental, educação estética e educação patrimonial. Revista Ibero-Americana de Ciências Ambientais, v.8, n.3, p.211-227, 2017. DOI:

http://doi.org/10.6008/SPC2179-6858.2017.003.0020 


\section{INTRODUÇÃO}

Os estudos do campo socioambiental e do patrimônio cultural, a começar pela contextualização das raízes do conjunto de crises e transições paradigmáticas em curso, explicitam as consequências da modernidade (conhecimento centrado na razão pura) e da pós-modernidade, com destaque para a crise socioambiental, bem como as crises do saber e do conhecimento abordadas por Flusser (1998; 2008), Maffesoli (1984; 1989; 1991; 1998), Leff (2003), Santos (2000; 2002; 2003) e Latour (2004); crise dos sentidos e de percepção - processo de anestesia e perda progressiva do imaginário, estudadas por Maffesoli (1984) e Duarte Junior (1997; 2000; 2001); crise da Educação e seu paradigma educacional emergente por Moraes (1997); e crise da identidade - deslocamento e fragmentação do indivíduo moderno com Hall (1996; 2000).

Essa conjuntura de crises está associada à insustentabilidade dos atuais modelos de desenvolvimento e a emergência, por exemplo, de um 'saber' e uma 'racionalidade ambiental' conforme Leff (2000a; 2000b; 2003); do paradigma da inter e transdisciplinaridade segundo, Fazenda (1994; 1995; 2008; 2010), Moraes (2003; 2004) e do pensamento complexo e diálogo de saberes com Morin $(2000 ; 2001 ; 2005)$ e do diálogo em Buber (1979; 2005).

Esse quadro geral de crises, conflitos e rupturas paradigmáticas, desafia o mundo contemporâneo a trilhar os caminhos que levem à construção de sociedades sustentáveis. Esse desafio se assevera num cenário de perspectivas e tendências que parece negligenciar e, até mesmo, negar os fatos associados às Mudanças Globais. Os campos Socioambiental, da Educação, da Cultura e do Patrimônio têm papéis vitais na superação dessas crises e equacionamento dos dilemas apresentados por elas à humanidade.

Diante desse quadro, a Educação Ambiental, Estética e Patrimonial são chamadas a se reposicionarem e redefinirem seus papéis, visto que os campos em que se inserem também são constituintes desse modelo civilizatório hegemônico e insustentável, o que exige, segundo Leff (2000a), a emergência de novos paradigmas de compreensão de realidades pelo encontro da epistemologia com a hermenêutica. Ou seja, ultrapassa a mera integração entre sociedade-natureza e pressupõe uma abertura para o diálogo de saberes e a hibridização entre, ciências, tecnologias e saberes.

Para esse reposicionamento da Educação Ambiental, Estética e Patrimonial é necessário uma profunda reflexão sobre as bases epistemológicas, filosóficas e metodológicas que as sustentam. Segundo Brügger (2006), a expressão 'crise ambiental' tem sido banalizada sendo "na verdade, e cada vez mais, uma crise muito mais profunda que envolve um paradigma, um projeto de mundo e um modelo de sociedade que emergiu a partir desse paradigma e desse específico projeto de mundo". Desse projeto e paradigma dominante, instaura-se uma "profunda dicotomia sociedade-natureza que impregna das mais variadas formas o nosso mundo vivido - e limita a possibilidade de um campo de experiência mais abrangente".

Assim, percebe-se claramente que estas problemáticas estão associadas, a princípio, à necessária reforma do pensamento, o que envolve processos culturais e educacionais transformadores. Ainda estamos sob forte influência das consequências da modernidade nos vários campos de conhecimento, caracterizando um momento histórico, que nos coloca a questionar e refletir, de maneira profunda, o que queremos com o conhecimento que construímos e como este conhecimento transforma a nós, como seres humanos, e todas 
as relações que estabelecemos com o mundo e a vida. O que tem implicações diretas ao campo da Educação de forma ampla e, específica, para a Educação Estética, Educação Ambiental e Educação Patrimonial. É neste contexto que se objetiva estabelecer um diálogo entre a Educação Ambiental e a Educação Patrimonial, em busca de convergências e similaridades entre elas, ainda que por uma revisão teórica e limitada pesquisa bibliográfica.

\section{METODOLOGIA}

A metodologia se baseou na pesquisa da literatura científica sobre o tema, em abordagem generalista e com recortes na busca de possíveis similaridades e convergências epistemológicas, históricas e metodológicas entre os $\operatorname{campos}^{1}$ da Educação Ambiental, Educação Patrimonial e Educação Estética. Não se pretende uma revisão aprofundada de toda literatura disponível nessas três grandes áreas de saber, mas sim, estabelecer um diálogo inicial a partir de determinadas publicações que, ao nosso ver, permitem identificar algumas similaridades e convergências, e assim evidenciar lacunas a serem preenchidas por pesquisas futuras.

\section{DISCUSSÃO TEÓRICA}

A Educação Ambiental e Patrimonial, ambas em suas essências, são reconhecidas como processos presentes ao longo da história adquirindo diferentes conceituações o que suscita comumente a clássica pergunta: 'Mas o que é, afinal, Educação Patrimonial?'. E, da mesma forma, 'o que é Educação Ambiental?'; 'O que entendemos por Educação Ambiental?'; 'E Educação Patrimonial?'; 'Quais seus fundamentos, princípios e objetivos frente ao contexto histórico em que estamos?'.

\section{Educação Ambiental, Patrimonial e Estética: em busca de convergências e similaridades}

Numa primeira incursão visando sistematizar os principais aspectos epistemológicos da Educação Patrimonial (EP), dependendo do filtro que se utilizar para essa análise, percebem-se várias convergências e similaridades com os processos históricos de constituição do campo da Educação Ambiental e, de forma implícita, com a Educação Estética.

\section{Educação Estética - do sensível ao inteligível}

Quanto à Educação Estética, destacam-se algumas dimensões e problemáticas, que no nosso entender, explicitam potenciais conexões com a Educação Ambiental e Patrimonial. Duarte Junior (2000), ao sentenciar que "o mundo, antes de ser tomado como matéria inteligível, surge a nós como objeto sensível", pretende distinguir e correlacionar ambos os termos sensível e inteligível. Ao que atribui ao sensível como o

\footnotetext{
${ }^{1}$ Referente ao conceito de campo proposto Pierre Bourdieu (2005) indicando a natureza relacional tanto da Educação Ambiental como Patrimonial as quais estão em constante relação e movimento dentro de um jogo de agentes, sejam indivíduos ou instituições, os quais criam os espaços e os fazem existir pelas relações que se estabelecem. Esse jogo de forças (ou capitais) demarca um campo de lutas, confrontos, tensões, poder e tomada de posição para se conservar ou transformar o próprio campo em que se inserem seus agentes. Um dos princípios dos campos, à medida que determina o que os agentes podem ou não fazer, é a "estrutura das relações objetivas entre os diferentes agentes" (PEREIRA, 2015, citado por BOURDIEU, 2004).
} 
objeto próprio do conhecimento sensível, as sensibilidades e subjetividades, assim como o inteligível é o objeto próprio do conhecimento intelectivo, mais objetivo e racional.

Fundamenta-se em Maffesoli e Merleau-Ponty para propor um projeto radical de retorno à raiz grega da palavra "estética" - "aisthesis, indicativa da primordial capacidade do ser humano de sentir a si próprio e ao mundo num todo integrado". Evidencia a urgência em se dar a devida atenção a uma educação do sensivel, a uma educação do sentimento, que se pode muito bem ser chamada de educação estética.

Destaca que vivemos anestesiados, sob o efeito de nossa educação e da mídia. A anestesia paralisaria nossos sentidos, como para receber uma intervenção cirúrgica, ao passo que uma educação estésica nos devolveria à nossa consciência e à nossa sensibilidade. Para Duarte Junior (2000), a educação estética nos conecta com o prazer de ensinar, aprender e transformar a realidade.

Esta crise de percepção, de sentido e da imaginação pode ser considerada, segundo Maffesoli (1998), como consequência de um erro epistemológico só aceitável no período da modernidade em que se tratava de dominar a natureza. Mas, já não se justifica insistir nesse erro quando a "relação com a natureza, seja a do corpo individual ou a do ambiente propriamente dito, tende a tornar-se mais 'parcerial'". Destaca ainda que a "ecologização do mundo deve corresponder uma ecologia do espírito" (MAFFESOLI, 1984).

Quanto a educação dos sentidos, Duarte Junior (2000), assim como Le Breton (2016), destacam a função do corpo e corporalidade sensível enquanto condição de existência humana considerando que "a experiência sensorial e perceptiva do mundo se instaura na relação recíproca entre o sujeito e seu ambiente humano e ecológico [...] e o conhecimento sensível alarga-se sem cessar pela experiência acumulada ou pela aprendizagem". Essas essencialidades reforçam as dimensões do sensível e do inteligível contextualizadas na educação estética.

Paulo Freire também se referiu à anestesia, ao contrapor sua educação problematizadora à educação bancária, ao afirmar que essa "implica numa espécie de anestesia, inibindo o poder criador dos educandos, a educação problematizadora, de caráter autenticamente reflexivo, implica um constante ato de desvelamento da realidade" (FREIRE, 1988).

Com "As três ecologias" e "Caosmose: um novo paradigma estético", Félix Guattari (1990; 1992) lança o conceito de ecosofia e coloca a construção dos espaços e das subjetividades como uma das principais discussões da contemporaneidade. Nessa perspectiva reconhece que o enfrentamento e a superação da crise ecológica não poderá ser apenas pela abordagem tecnocrática dos danos industriais, mas sim, ampliando para uma abordagem ético-estética e política envolvendo as três ecologias (ambiental, social e a subjetividade humana). Instaura-se um horizonte de mudança de paradigma existencial, onde a noção de subjetividade está associada às dimensões ético-estéticas.

Esta perda da produção de subjetividade, levantadas por Guattari (1990; 1992), verifica-se em muitos processos educativos tradicionais sendo preocupante, além desse, o fato da expropriação da capacidade de simbolizar e metaforizar a vida, que segundo Castell (2007), "se encontra imbricada com todo um processo de educação não-formal e formal de extrema complexidade, que não estimula a produção simbólica - pelo contrário, propõe a reprodução de padrões e estereótipos". 
Algumas pesquisas e publicações específicas sobre as relações entre 'sensibilização' e 'educação ambiental' começam a aparecer, dentre as quais destacamos as dissertações de: Schmidt (2003), Ana Moura (2004) e Teodoro (2011); os livros: Verde Perto (RODRIGUES et al., 2015); Pela Trilha da Sensibilidade (ADAMS, 2015); Vivências com a Natureza (CORNELL, 2008a; 2008b); À sombra das árvores: transdisciplinaridade e educação ambiental em atividades extraclasse (MENDONÇA et al.,2003); Alfabetização Ecológica (CAPRA, 2006); o documento técnico sobre O Desafio do Movimento Sharing Nature na Educação Ambiental Contemporânea (FURIHATA et al., 2006); A educação ambiental através do contato dirigido com a natureza (NEIMAN, 2007); e a edição dos cadernos de roteiros Olhar perceptivo: atividades de sensopercepção em ações de educação ambiental (ALVES et al., 2010).

É pertinente também a crítica feita por Sorrentino et al. $(2009 ; 2010)$ sobre a prevalência de algumas dessas atividades de sensibilização e interpretação da natureza (CORNELL, 1996) e alfabetização ecológica (CAPRA et al., 2006), fortemente vinculadas a concepções naturalistas na Educação Ambiental, as quais, "para se tornarem real e eficaz letramento ambiental, precisam propiciar a interpretação de nossas sociedades e do papel que nelas desempenhamos".

Quanto ao risco de se banalizar as práticas de educação ambiental por fragilidades teóricas e metodológicas, Sorrentino et al. (2010), chamam a atenção para a precariedade da formação de profissionais habilitados para atuar na formulação e implantação de políticas públicas de Educação Ambiental tanto nas esferas pública (federal, estadual e municipal) como no setor produtivo e na sociedade civil organizada. Observa-se também o surgimento, nos campos da Educação Ambiental e Educação Estética, de um constructo específico denominado "Arte-Educação Ambiental” (RACHE, 2015; 2016; ROCHA, 1997; 1999).

Na área da Educação Física pode-se citar a Educação do Corpomundo - princípios éticos, estéticos e ecológicos no fortalecimento da sensibilidade humana (MELO et al., 2007) e Silva (2007), para quem a Educação do CorpoMundo se pauta numa educação estética, associada à Teoria das Cinco Peles de Hundertwasser, no aprendizado sequencial de Joseph Cornell (2008a; 2008b) e pela ecosofia de Guattari (1990). Nessa proposta, a possibilidade para refletir/sensibilizar é priorizada, onde a "racionalidade humana não é desprezada, mas que ela não impossibilite outras formas de sensações e sensibilidades, na relação com o ritmo harmônico/desarmônico do movimento da vida; movimentos do corpo" (SILVA, 2007).

Apesar de ser uma importante contribuição ao campo da Educação Ambiental no Brasil, tais produções e sistematização de experiências são insuficientes para abranger temas tão complexos e urgentes como é a educação do sensível, Educação Estética e a própria Educação Ambiental. Soma-se a esse contexto a Educação Patrimonial que embora possua muitas convergências, ainda é uma área a ser considerada nas pesquisas e projetos de Educação Ambiental.

\section{Educação Ambiental e Educação Patrimonial}

No que se refere à comparação entre Educação Patrimonial e Educação Ambiental, chama a atenção que ambas se defrontam frequentemente com o desafio de se definirem e se conceituarem, apresentando 
diferentes concepções e vertentes teóricas, filosóficas e metodológicas fortemente agenciadas pelos campos socioambiental, da educação e do patrimônio cultural, aos quais se incorpora o patrimônio natural.

A busca por suas próprias identidades, quase que num processo de subjetivação, é constante e de certa forma recente sendo que a Educação Ambiental (1960-1970) tem surgido com esse nome, no Brasil, um pouco antes do que a Patrimonial (1980-1990). Em sua maioria, ambas são efetivadas via atividades, ações, eventos e projetos de curto a médios prazos, sendo exceções o desenvolvimento de atividades ligadas à execução de projetos de longo prazo ou mesmo de caráter permanente. O que leva muitas vezes ao contingenciamento de certo projetismo ${ }^{2}$ nem sempre direcionado ao que realmente é necessário, mas sim as exigências e ao perfil do edital ou fonte disponível de financiamento no momento.

Há ainda outro ponto de convergência extremamente relevante que é o fato de estarem associadas a algo marginal (à margem), secundário, periférico, embora estejam presentes nos discursos institucionais e até mesmo de gestores e educadores como sendo de suma importância, mas que não se verifica objetivamente na prática. Um descompasso entre o que se diz e o que se faz se manifesta associado à discussão entre 'centro' e 'periferia' nas críticas ao modelo de desenvolvimento hegemônico globalizado.

A Educação Ambiental teve uma aplicação anterior e de maior abrangência no país sendo que, de acordo com Souza (2014), apesar de antiga, a Educação Patrimonial é uma expressão adotada há poucos anos no Brasil e seu uso nos procedimentos de patrimonialização é marginalizada. Dentre as razões apontadas desse uso secundário, destaca-se um entendimento limitado de que a Educação Patrimonial deva ser aplicada apenas após os processos de patrimonialização reduzindo-se à função muito mais informativa de valorização desse patrimônio. Assim como na Educação Ambiental, esta redução é questionada e problematizada provocando outras concepções e correntes mais progressivas, críticas e emancipatórias no que se refere ao processo educativo. Outro ponto relevante indicado por Souza (2014), é a tendência de a Educação Patrimonial priorizar processos participativos e dialógicos em termos de patrimonialização, influenciados pelo advento da Diversidade Cultural no bojo da Contracultura, dos Estudos Culturais e das militâncias em favor dos Direitos Civis.

A busca por referenciais teóricos e históricos sobre Educação Patrimonial e consequente análise crítica sobre sua práxis, evidenciou uma produção acadêmica bastante assimétrica e desproporcional ao que já se tem sistematizado em termos de produção acadêmica sobre Educação Ambiental. Nisso, há um descompasso que precisa ser analisado com mais critério oportunamente, visto que ambas estão mais próximas do que se imagina à primeira vista. Se aguçar o olhar, a leitura e a escuta sobre a Educação Patrimonial encontrar-se-á uma enorme afinidade em propósitos e desafios. Ainda mais ao se considerar a unidade dialética entre natural-cultural já amplamente problematizada pelo campo socioambiental.

\footnotetext{
2 O termo "projetismo" (LITTLE, 1998; PARESCHI, 2002) tem sido utilizado para designar uma modalidade especifica atuação no campo socioambiental cujas atividades são dependentes da realização de projetos atrelados a demanda de financiamento governamental, privado ou do terceiro setor, ficando sua continuidade limitada a oferta e aprovação dos referidos editais. Há sério risco de se desviar das reais necessidades e demandas locais, priorizando ou mesmo se adequando as diretrizes dos editais de financiamento ou patrocínio disponíveis. Nessa modalidade não é possível contemplar a sofisticada dinâmica das comunidades e realidade locais frente a lógica dos projetos de curto prazo. Sua lógica acaba por fragmentar ainda mais as relações inter e intracomunitárias e institucionais.
} 
Pesquisadores, Educadores e Filósofos têm se dedicado a categorização e taxonomia das diferentes concepções e práticas da Educação Ambiental desde a década de 1990 até o momento. Em período anterior, as publicações disponíveis eram escassas e raras. Em curto espaço de tempo 'pós-Rio 92', ocorreu um crescimento vertiginoso na produção acadêmica em Educação Ambiental e áreas correlatas a ponto do Brasil ser hoje, reconhecidamente, um país de referência em termos teóricos, filosóficos, metodológicos e de políticas públicas em Educação Ambiental.

Os conceitos-chave e fundamentos teóricos e filosóficos essenciais para se fazer Educação Ambiental foram agrupados e sistematizados em publicações específicas visando a formação de educadores ambiental, a partir de 2005 com a série de publicações do Órgão Gestor (OG) da Política Nacional de Educação Ambiental (PNEA) e consequente Programa (ProNEA). Em especial, do livro "Identidades da Educação Ambiental Brasileira" (LAYRARGUES, 2004) e os três volumes da série "Encontros e Caminhos: Formação de Educadoras(es) Ambientais e Coletivos Educadores" (FERRARO JUNIOR, 2005; 2007; 2014), num esforço de se atender as necessidades de formação do educador ambiental no país.

Nesse contexto, é inevitável referenciar o momento em que a Educação Patrimonial passa oficialmente a ser nomeada no Brasil em 1983, no 10 Seminário Sobre o Uso Educacional de Museus e Monumentos, realizado pelo Museu Imperial de Petrópolis/RJ. Um dos resultados efetivos desse evento foi a elaboração do Guia Básico de Educação Patrimonial (HORTA et al., 1999), vindo a ser editado apenas em 1999. De acordo com Souza (2014), a Educação Patrimonial colocada nesse momento "foi inspirada no trabalho pedagógico desenvolvido na Inglaterra sob a designação de Heritage Education" (HORTA et al., 1999). Essa obra foi “reeditada em 2005 e em 2006, seguida pelo Manual de Atividades Práticas de Educação Patrimonial” (GRUNBERG, 2007). O referido Guia começa questionando 'o que é, afinal, a educação patrimonial?'. Horta et al. (1999) considera que:

Trata-se de um processo permanente e sistemático de trabalho educacional centrado no Patrimônio Cultural como fonte primária de conhecimento e enriquecimento individual e coletivo. A partir da experiência e do contato direto com as evidências e manifestações da cultura, em todos os seus múltiplos aspectos, sentidos e significados, o trabalho da Educação Patrimonial busca levar as crianças e adultos a um processo ativo de conhecimento, apropriação e valorização de sua herança cultural, capacitando-os para um melhor usufruto destes bens, e propiciando a geração e a produção de novos conhecimentos, num processo contínuo de criação cultural.

A partir da publicação e difusão deste Guia, apresentou-se, aos profissionais que lidam com o Patrimônio Cultural, as orientações metodológicas mínimas para balizarem suas atividades de Educação Patrimonial. O Guia funcionou como referência obrigatória, cuja abordagem metodológica acabou "sendo reproduzidas em todos os cantos do Brasil, como atestam as publicações dos primeiros anos do século XXI" (Soares et al., 2003; 2008). A metodologia contempla quatro etapas sequenciais envolvendo observação, registro, exploração e apropriação, sendo indicados os recursos (estratégias) e objetivos para cada uma delas.

Desde então, tem-se disseminado e provocado críticas sobre possíveis lacunas, limitações e até equívocos conceituais e metodológicos por pesquisadores e educadores da área a exemplo de Souza (2011; 2014), Soares (2003; 2007; 2008; 2009), Galzerani (2010; 2013), Casco (2005), Pelegrini (2006), Tolentino (2012), Florêncio (2012; 2014), e Zanirato et al., (2006), que fazem contribuições significativas a 
epistemologia da Educação Patrimonial, assim como eventuais críticas considerando-a como uma metodologia que precisa ser problematizada a luz dos novos contextos e atualizações ocorridas tanto na Educação como no Patrimônio Cultural e nos Estudos Culturais.

Via de regra, o IPHAN tem sido o principal órgão catalisador e difusor da Educação Patrimonial no Brasil e, segundo Souza (2014), "as experiências emergidas nas organizações da sociedade civil vêm ganhando corpo, pressionando o Estado a se adequar às múltiplas possibilidades existentes nas culturas brasileiras".

Com a incorporação mais recente dos elementos intangíveis da cultura nos processos de patrimonialização, amplia-se e a noção de Educação para o Patrimônio, segundo o autor [...] "necessitando de reflexões que abarquem novos métodos e agentes, diferentes materiais, didáticas inovadoras, e, principalmente, um posicionamento político-pedagógico adequado aos anseios da população ou que dela emirja" (SOUZA, 2014).

A analogia de percursos similares entre Educação Patrimonial e Educação Ambiental também se verifica na definição de procedimentos e abordagens metodológicas coerentes com as diferentes concepções e teorias que as impactam. Soares (2009) destaca uma discussão pertinente e pouco explorada é que, 'sendo a Educação Patrimonial uma metodologia, a qual teoria se aplica?'. E complementa, destacando a aproximação entre Educação Patrimonial e a educação libertadora de Paulo Freire, a qual é também defendida por outros autores (SOARES, 2009).

Análise similar é feita por Souza (2014) ao apontar uma disputa entre correntes teóricas divergentes entre os que concebem a Educação Patrimonial enquanto instrumento de libertação e aqueles mais sectários, que promovem uma educação mais conservadora. Destaca que essa confronto se manifesta dentro do próprio IPHAN, no qual encontram-se os diálogos freirianos, os instrucionistas reacionários e os que atribuem a Educação Patrimonial como uma invenção descabida (SOUZA, 2014).

Educação Ambiental e Patrimonial enfrentaram (e ainda enfrentam) o debate sobre as concepções de Educação e consequente adjetivação associadas ao Ambiente e ao Patrimônio, mas em períodos diferenciados. Primeiramente, na Educação Ambiental, Sato (1997) utilizou a classificação de Robbotom et al. (1993) caracterizada por: Educação sobre o Ambiente, Educação no Ambiente e Educação para o Ambiente. Já no campo patrimonial, Gil et al. (2014) destaca que muito já se questionou sobre o termo Educação Patrimonial, e se propôs falar em educação para o patrimônio, educação com o patrimônio, patrimônio e educação.

A relação entre Educação Ambiental e Educação Patrimonial também foi abordada por Pelegrini (2006) a partir da análise das categorias chaves para ambas, ou seja, a relação entre cultura e natureza a partir dos desafios das práticas preservacionistas na esfera do patrimônio cultural e ambiental. $\mathrm{O}$ artigo observa que, historicamente, muitas das iniciativas de preservação ambiental e do patrimônio cultural acabaram por desconsiderar e até mesmo excluir as comunidades locais, populações residentes na área e entorno dos sítios e centros históricos e culturais bem como de áreas preservadas e unidades de conservação. E, de forma geral, considera que as áreas preservadas e dos centros históricos latino-americanos parecem 
enfrentar questões similares em termos de degradação ambiental e dos bens culturais comumente associadas à especulação do solo urbano e a privatização.

Problematiza a associação dos bens culturais ao seu valor de mercado, a evolução do conceito de patrimônio e cultura assim como de ambiente incorporando aspectos sociais, culturais e econômicos destacando que na passagem do século XX para XXI, "já se depreende que essas áreas se inter-relacionam e que, independentemente das suas respectivas categorias, todo o patrimônio se configura e se engendra mediante suas relações com a cultura e o meio" (PELEGRINI, 2006).

Essa mudança de concepção e práticas associadas tanto à preservação do patrimônio cultural quanto ambiental indica que a partir do século XXI, ocorre o reconhecimento das chamadas populações tradicionais e consequente contribuição para a conservação e manejo da diversidade biológica. "Fato que influência o surgimento de um ecologismo diferenciado daquele que, séculos antes, sacralizavam o mito da natureza intocada" (PELEGRINI, 2006).

Scifoni (2006) estuda o processo de construção da ideia de patrimônio natural e das políticas públicas para a sua proteção no litoral norte paulista analisando as consequências do tombamento da Serra do Mar na produção do espaço geográfico. Conclui que a proteção da natureza aparece, ao mesmo tempo, como produto do urbano e como condição para a sua reprodução. Sua análise passa pela contextualização das tendências de patrimonialização e consequente 'excesso de patrimônio', tendo como referência Jeudy (2005), o qual faz ressalvas quanto a generalizações sobre os modismos da patrimonialização. Destaca, no entanto, que as precárias condições de boa parte do patrimônio e as dificuldades de atuação dos órgãos públicos revelam que estamos distantes de um quadro que poderia qualificar como "excesso de patrimônio" (SCIFONI, 2006).

Quanto ao patrimônio natural, Scifoni (2006), afirma que, no plano da pesquisa científica ou na esfera institucional, há um vazio evidenciado pela raridade de pesquisas sobre o tema associado à gestão pública, além do fato de o patrimônio natural ser uma questão secundária, até mesmo "marginal", para os órgãos responsáveis. Cabe destacar que isso se deve, também, pelo fato de o patrimônio natural ter ficado de fora do processo de unificação das diversas categorias de áreas protegidas ocorrido com a efetivação do Sistema Nacional de Unidades de Conservação.

Uma das razões para isso é porque está sujeito ao setor da cultura e não do meio ambiente. Isto lhe confere uma singularidade enquanto mecanismo de proteção ambiental e cultural. O patrimônio natural acaba sendo um instrumento de proteção ambiental sob controle das políticas culturais e fora do controle ambiental (SCIFONI, 2006). Este é mais um exemplo do quanto a distinção entre esses dois campos - o ambiental e o cultural, somado à fragmentação das políticas públicas e a departamentalização dos órgãos gestores, são problemas estruturais para a gestão integrada e compartilhada do patrimônio.

Novamente, surge a necessidade de pensar e problematizar a questão a partir do campo teórico e prático da interdisciplinaridade, buscar experiências concretas que estejam sendo conduzidas nessa perspectiva e/ou eleger estudos de caso, como experiência piloto, envolvendo as universidades e instituições afins em novos modelos de gestão, tanto das Unidades de Conservação como do Patrimônio Cultural. 
Nessa evolução conceitual, registra-se o fato histórico da Convenção para a Proteção do Patrimônio Mundial, Cultural e Natural, aprovada em 1972, ter estabelecido duas categorias diferentes de inscrição de bens como patrimônio: patrimônio natural e patrimônio cultural. De acordo com Santilli (2016), havia um antagonismo entre as categorias cultural e natural, reflexo da origem bipartite das políticas internacionais de patrimônio, oriundas de dois movimentos distintos: um que se preocupava com os sítios culturais e outro que lutava pela conservação da natureza (SANTILLI, 2016). Como esforço de superar esta dicotomia, surge em 1992, uma nova categoria do patrimônio denominada "Paisagem Cultural" ${ }^{3}$. Sua proposição ocorreu na 16a Sessão do Comitê do Patrimônio Mundial, realizada no dia 10 de Julho de 1992, e tem sido foco de discussões internacionais nos campos do patrimônio e do ambiente. A expressão "Paisagem Cultural" já envolve duas grandes áreas - paisagem e cultural, estabelecendo o diálogo entre elas. Torna-se óbvio a necessidade de se adentrar ao campo teórico dos estudos de paisagem por um lado, e, por outro, dos estudos culturais.

No cenário brasileiro, destaca-se Jornada "Paisagens culturais: novos conceitos, novos desafios", realizada em Bagé/RS, no dia 17 de agosto de 2007, que elaborou a Carta de Bagé ${ }^{4}$ definindo a paisagem cultural como sendo o "meio natural ao qual o ser humano imprimiu as marcas de suas ações e formas de expressão, resultando em uma soma de todos os testemunhos resultantes da interação do homem com a natureza, e, reciprocamente, da natureza com o homem".

Para Dalonso (2016), a paisagem cultural "é considerada no campo patrimonial por seu conjunto híbrido, como um palimpsesto que representa a cultura material, imaterial, seus usos, saberes, fazeres e faz interface com os espaços naturais". Oliveira et al. (1989) considera as paisagens como inerentes a nossa condição de vida, tornando-se um problema existencial humano, pois é muito mais que apenas uma estrutura holística que lhe da forma e fisionomia, mas também, um espaço vivido e sistema de relações ao mesmo tempo. Conclui que o "problema não é apenas intelectual, mas envolve uma intensa experiência humana com os lugares e suas paisagens, através de profundos vínculos cognitivos e efetivos, que ainda não foram devidamente identificados e estudados" (OLIVEIRA et al., 1989).

A abordagem de "Paisagem Cultural" trouxe uma complexidade a mais para temática patrimônio natural quando esta se articula à noção de paisagem incluindo, portanto, as relações do ser humano com o meio, cujos "modos" ou "gêneros" do viver produzem "paisagens culturais". Pelegrini (2006), destaca que as especificidades "relacionais entre as culturas e o meio ambiente definem, conforme os fundamentos da geografia cultural, os traços da própria paisagem e a distinguem de outros espaços, determinando o seu 'geni'us loci', ou seja, a 'alma do lugar'”. Já Oliveira et al. (1989) conclui que a "questão básica que se coloca

\footnotetext{
${ }^{3}$ Santilli (2016) apresenta a seguinte descrição: As paisagens culturais são classificadas em três categorias, para fins de inscrição como patrimônio mundial: a) paisagens claramente definidas (clearly defined landscapes), que são aquelas desenhadas e criadas intencionalmente, como jardins e parques construídos por razões estéticas; b) paisagens evoluídas organicamente (organically evolved landscapes), também chamadas de "essencialmente evolutivas", que se subdividem em paisagens-relíquia ou fóssil (relict or fossil landscapes), cujo processo de construção terminou no passado, e paisagens contínuas ou vivas (continuing landscapes), em que os processos evolutivos ainda estão em curso; paisagens culturais associativas (associative cultural landscapes), que têm o seu valor determinado de acordo com associações feitas acerca delas, como as associações espirituais de povos tradicionais com determinadas paisagens.

${ }^{4}$ Carta de Bagé ou Carta da Paisagem Cultural foi aprovada durante a Jornada "Paisagens culturais: novos conceitos, novos desafios", realizada em Bagé, Rio Grande do Sul, no dia 17/8/2007.
} 
não é mais a de que se devem ou não recriar as paisagens, mas de que maneira isso pode ser alcançado com responsabilidade e com base na percepção e na experiência dos usuários". É a partir desse contexto que a interface "Paisagem/Cultural", a nosso ver, cria uma terceira faceta essencial nessa articulação que vem a ser a "Percepção Ambiental" e, por consequência, a "Interpretação Ambiental" 5.

Pesquisas de percepção ambiental estão disseminadas e são muito associadas às unidades de conservação a exemplo da caracterização perceptiva da Estação Ecológica de Jataí (Luiz Antônio/SP) por diferentes grupos socioculturais de interação (SANTOS, 2000). As Unidades de Conservação são áreas protegidas privilegiadas nesse sentido, uma vez que dão concretude às propostas idealizadas sobre paisagem, patrimônio e a própria conservação da sociobiodiversidade. Dalonso (2016) destaca que "há uma crescente evidência de fortes ligações entre a paisagem cultural e as áreas protegidas" (PHILLIPS, 2003; RÖSSLER et al., 2005; RÖSSLER, 2006 citado por FINKE, 2013).

Recomenda-se que a Educação Patrimonial e Ambiental devem ser tomadas como instrumentos para a construção da cidadania e que, aos poucos, "a sociedade brasileira começa a se convencer de que é possível compatibilizar a preservação patrimonial e ambiental ao desenvolvimento sustentável" (PELEGRINI, 2006). Nesse imbricamento entre EE, EP e EA, o campo do patrimônio cultural, em especial, aqueles engajados com o Movimento Internacional para uma Nova Museologia - MINOM e com as propostas de 'ecomuseu', evidencia enorme potencialidade de contribuições recíprocas.

Para Duarte (2013), a “Nova Museologia é um movimento de larga abrangência teórica e metodológica, cujos posicionamentos são ainda centrais para uma efetiva renovação de todos os museus do século XXI". Ganha relevância no sentido de aproximar o campo museológico à educação popular com envolvimento comunitário defendido como forma de se contrapor a clássica função dos museus, tradicionalmente tidos como a serviço das elites sociais e intelectuais. Este Movimento foi fortemente influenciado pelas ideias inovadoras de George Henri Rivière e suas teorias museológicas defendidas e aplicadas no Musée National des Arts et Traditions Populaires, em Paris.

No contexto deste artigo, é pertinente fazer um recorte destacando o surgimento das concepções e propostas de 'Museu Integral' e 'Ecomuseu' sendo este, um termo cunhado em 1971, pelo então Diretor do Conselho Internacional de Museus (ICOM), Hugues de Varine-Bohan, no contexto da IX Conferência Geral de Museus do ICOM - realizada em Grenoble (França) e dedicada à discussão das funções do museu ao serviço do ser humano. Esse recorte é feito a partir da convergência de questões pertinentes a conservação das diversidades biológicas e culturais entendidas como uma unidade de patrimônio natural-cultural com envolvimento direto das comunidades locais e populações tradicionais em seus processos de criação e manutenção/manejo e gestão compartilhada visando o desenvolvimento cultural, social e econômico.

\footnotetext{
${ }^{5}$ Pode-se acrescentar mais um desdobramento desse binômio Percepção-Interpretação Ambiental referente às Representações, as quais não são objeto deste artigo, mas merece registro.

${ }^{6}$ Cabe aqui uma ressalva quanto ao uso generalizado do termo "Desenvolvimento Sustentável", o qual é polissêmico e tem uma crítica já sistematizada em especial a partir do campo da Educação Ambiental a qual se vincula mais fortemente, no Brasil e América Latina, ao conceito de "Sociedades Sustentáveis". O documento de referência nesse contexto é "O Tratado de Educação Ambiental Para Sociedades Sustentáveis e Responsabilidade Global" construído pelo Fórum Global no Rio de Janeiro em 1992. Desde então tem sido atualizado e discutido internacionalmente por meio de eventos de Educação Ambiental. O tratado inspirou a Política Nacional de Educação Ambiental, que legisla sobre o tema desde 1999.
} 
A esse respeito, Duarte (2013) destaca que foi em setembro de 1966, na França, que se discutiu a constituição dos Parques Naturais enquanto estruturas capazes de promover a defesa do patrimônio cultural e natural tendo como defensor Rivière, para quem os Parques deveriam incluir "recintos explorados museograficamente". A partir de então são inseridas as chamadas 'casas parque', entendidas como antecessoras imediatos do ecomuseu.

Varine (2007), propõe que cada ecomuseu criará seu próprio conceito e sua definição em função de seus objetivos, das culturas locais e do contexto de desenvolvimento local - cultural, social e econômico - e também das ideias, utopias e personalidade de seus promotores. Registra que foi na Assembleia Geral do ICOM de 1971, um ano antes da primeira Assembleia das Nações Unidades sobre Meio Ambiente e Desenvolvimento Humano, realizada em Estocolmo, em 1972, que surgiu a ideia de reivindicar um papel importante para os museus de ciências naturais dentro do campo da educação em matéria de ecologia e meio ambiente. A pedido do ministro francês de meio ambiente, o termo 'Ecomuseu' deveria refletir e contemplar essa preocupação e, em especial, designar as "casas" dos parques naturais regionais que estavam sendo criados na França. Destaca que foi na reunião internacional do ICOM em 1972 que se elaborou uma definição oficial de 'Ecomuseu' redigida por Georges Henri Rivière, o qual a aprimorou até a década de 1980. Tal conceito tem sido objeto de estudos e problematizações desde então se tornando difundido em todo o mundo sendo hoje em dia considerado, por Varine (2007), que um ecomuseu se trata de um museu para a Agenda $21^{7}$.

Uma característica do ecomuseu, segundo Varine (2007) é que ele deve fazer parte dos instrumentos da dimensão cultural do desenvolvimento local, pois está enraizado na cultura viva de seus habitantes. E que atualmente há um generalizado uso do termo ecomuseu podendo este se referir a qualquer coisa, desde um pequeno museu local, completamente amador, até uma instituição sofisticada, ou ainda um projeto 'político' para a participação dos cidadãos no desenvolvimento de seu território. Defende a nível pessoal que se deveria até mesmo abandonar o uso inconsequente desse termo, já que não se tem garantido os seus princípios originários (VARINE, 2007).

Essa ideia de um projeto político de participação local relativa à Educação Patrimonial, vem de encontro a uma proposta análoga, originada na Educação Ambiental, das Salas Verdes ${ }^{8}$ e Coletivos Educadores $^{9}$ para Territórios Sustentáveis, os quais pressupõem a existência de um Projeto Político Pedagógico.

Ao analisar a difusão dos ecomuseus pelo mundo, Varine (2007), conclui que os países anglo-saxões são os mais reticentes e os países latino-americanos são os mais entusiastas. Já a Europa oriental, que

\footnotetext{
${ }^{7} \mathrm{O}$ Ministério do Meio Ambiente do Brasil considera que "A Agenda 21 pode ser definida como um instrumento de planejamento para a construção de sociedades sustentáveis, em diferentes bases geográficas, que concilia métodos de proteção ambiental, justiça social e eficiência econômica".

${ }^{8} \mathrm{O}$ Projeto Sala Verde, coordenado pelo Departamento de Educação Ambiental do Ministério do Meio Ambiente (DEA/MMA) consiste no incentivo à implantação de espaços socioambientais para atuarem como potenciais Centros de informação e Formação ambiental.

${ }^{9} \mathrm{O}$ papel de um Coletivo Educador é promover a articulação institucional e de políticas públicas, a reflexão crítica acerca da problemática socioambiental, o aprofundamento conceitual e criar condições para o desenvolvimento continuado de ações e processos de formação em Educação Ambiental com a população do contexto, visando a sinergia dos processos de aprendizagem que contribuem para a construção de territórios sustentáveis.
} 
durante muito tempo permaneceu a margem do movimento da nova museologia, vai incorporando a proposta pouco a pouco. Ásia e Pacífico estão começando a experimentar a partir de seus problemas específicos e de suas culturas. Na África, com exceção do Senegal, não existem experiências nesse sentido. Não hesita em dizer que a Europa é sem dúvida o continente mais conservador e que a América Latina é o mais inovador. Considera que as atuais emergências da crise socioambiental, a urgência na conservação, os riscos climáticos e o tráfico ilegal tem dominado a reflexão sobre uma eventual atualização de objetivos e métodos.

Uma evolução histórica no campo da Educação Ambiental é analisada por Andrade et al. (2014), evidenciando saltos qualitativos em suas práxis que inicialmente era caracterizada por ações pontuais e localizadas, típicas de eventos, passando para ações mais articuladas em redes mediante projetos e programas e mais recentemente evoluindo para articulação destes com as políticas públicas. O que, segundo Andrade et al. (2014), "insere educadores e educadoras ambientais em uma seara que não faz parte de seus processos de formação".

No contexto das Políticas Públicas de Educação Ambiental, Ferraro Junior et al. (2011) analisa como a crise do imaginário e colonialidade criam limites à Educação Ambiental na gestão pública. Ferraro Junior et al. (2011) considera o imaginário como campo mais profundo da criação política, o qual precisa ser compreendido minimamente para que se estabeleçam os diálogos qualificados necessários à crítica e a tomada de decisões nesse campo. Alertam para o fato de que o imaginário social de nossa época se reveste de uma aparente neutralidade da tecnociência criando as condições para formas de dominação nas quais dominados e dominantes partilham das mesmas representações (FERRARO JUNIOR et al., 2011).

A análise feita por Ferraro Junior et al. (2011), evidencia, entre outros, a monocultura da racionalidade da ciência, abordada por Santos (2002), como responsável pela hegemonia e neutralidade da tecnociência como condicionante do imaginário social de nossa época, como forma de enfrentar e superar essa crise do imaginário valorizam as dimensões e os sentidos dos coletivos enquanto fazer social transformador (FERRARO JUNIOR et al., 2011).

Ao transitar por esses três campos - Educação Estética, Patrimonial e Ambiental, fica evidente que elas se imbricam por meio de interfaces comuns, criando subáreas ou campos híbridos de ação. São pelas interfaces, pelos campos híbridos, que se estabelecem os diálogos de saberes e a interdisciplinaridade necessária para o pensamento sistêmico e complexo. Devido a essa complexidade, outras áreas acabam por se apresentar como integradoras como é o campo teórico da Percepção e, mais especificamente da Percepção Ambiental, da qual se origina a Interpretação Ambiental e, desta, resulta a Interpretação do Patrimônio conforme indica Aladrén et. al. (2006):

El concepto interpretación del patrimonio bebe en las esencias de la educación ambiental. En un principio se llamó interpretación ambiental y se empezó a utilizar hace más de cien años con los visitantes de los Parques Nacionales en Estados Unidos que, naturalmente, fueron los primeros destinatarios de la educación ambiental. Uno de los padres de la interpretación ambiental, Freeman Tilden (1957) fue el primero en definirla formalmente em los siguientes términos "Una actividad educacional que aspira a revelar los significados y las relaciones por medio del uso de objetos originales, a través de experiencias de primera mano, y por medios ilustrativos en lugar de comunicar información literal. 
Já é clássica a referência aos princípios da interpretação ambiental propostos, de forma pioneira, por Tilden (1957). O próprio título de um dos seus livros "Interpretando nosso Patrimônio" ("Interpreting our heritage") deixa claro a relação intrínseca entre "interpretação", "patrimônio" e "ambiente". Foi Tilden (1957) quem a definiu formalmente como sendo uma "atividade educacional que aspira revelar os significados e as relações por meio do uso de objetos originais, através de experiências de primeira mão, e por meios ilustrativos em lugar de comunicação literal".

\section{CONCLUSÕES}

Evidencia-se que a própria Educação Ambiental, assim como a Educação Patrimonial, influenciam e são influenciadas pelos contextos históricos a que estão submetidas, gerando uma polifonia e uma polissemia com a qual os profissionais, que atuam nestes respectivos campos, precisam ter domínio linguístico, sob pena de atravessamentos teóricos e metodológicos de toda sorte. A noção de polifonia no campo discursivo, considera que todo discurso é constituído por várias vozes na enunciação de um discurso. Costuma-se dizer que quando alguém anuncia um discurso, não anuncia só. A voz que fala se junta às outras vozes dos que já falaram sobre ou que ainda falam tal discurso.

Nesse sentido, todo discurso acaba sendo também polissêmico, com vários significados e sentidos, o que caracteriza a noção de polissemia. Da mesma forma, reconhece-se que o discurso é polissêmico porque ele é formado por partes de outros discursos gerando a interdiscursividade e intertextualidade, o que exige um trabalho de interpretação discursiva na busca dos sentidos e significados possíveis e pertinentes. Esta é uma tarefa cotidiana para todos educadores ambientais e do patrimônio que estejam realmente comprometidos, envolvidos e engajados com os desafios dos campos da Educação Ambiental e Patrimonial.

Com descompasso de mais de duas décadas é possível encontrar dilemas em ressignificações similares como, por exemplo, a contraposição de correntes e vertentes mais conservadoras, tradicionais, comportamentalistas versus correntes de uma educação libertária, transformadora, emancipatória, crítica fundamentada nas contribuições principalmente de Paulo Freire.

Destas convergências e similaridades, destaca-se o posicionamento que ambas assumem permitindo uma mesma perspectiva - ou seja, uma Educação Patrimonial e uma Educação Ambiental a partir da perspectiva crítica, emancipatória, libertária e transformadora, na qual os limites entre a educação formal ou em ambientes escolarizados, a não-formal - ou popular e em ambientes não-escolarizados, e a informal - ou difusa, precisam ser ressignificados.

Quando se busca abrir espaço neste campo e contemplar aspectos do sensível, do sutil, da fruição estética, do intuitivo, de intersubjetividades, corre-se o risco de ser associado com uma suposta falta de cientificidade ainda mais quando lidamos com a problemática socioambiental na qual as 'ciências duras' tem tido prevalência. Mesmo que esse caminho já esteja claramente indicado como inevitável para o conhecimento pertinente, à ciência e à educação, ainda se verifica certa desconsideração a ele no âmbito acadêmico e universitário. Assim a Educação Estética e do Sensível apresentam importantes contribuições para a práxis da Educação Ambiental e Patrimonial. Ou seja, integrar conhecimento sensível ao conhecimento 
inteligível é desafio dos mais contemporâneos no enfrentamento das sucessivas crises ambientais pela Educação Estética e muito pertinente também à Educação Ambiental e Patrimonial.

\section{REFERÊNCIAS}

ADAMS, B. G.. Pela trilha da sensibilidade. Novo Hamburgo: Apoema Cultura Ambiental, 2015.

ALADRÉN, P. E.; GRACIA, I. B.; LACOUTURE, H. B.; TOMÁS, J. O.. Sam Ham, que irás a los cielos: Algunas reflexiones sobre nuestras experiencias en Interpretación del Patrimonio (IP). Saragoça: CIAMA, 2006.

ALVES, D.; PERALVA, L. M.. Olhar perceptivo: atividades de sensopercepção em ações de educação ambiental: cadernos de roteiros. Brasília. IBAMA, 2010.

ANDRADE, D. F.; LUCA, A. Q.; CASTELLANO, M.; RISSATO, C. G.; SORRENTINO, M.. Da pedagogia à política e da política à pedagogia: uma abordagem sobre a construção de políticas públicas em Educação Ambiental no Brasil. Ciência \& Educação, v.20, n.4, p.817-832, 2014.

BRÜGGER, P.. O vôo da águia: reflexões sobre método interdisciplinaridade e meio ambiente. In: Educar em Revista, Curitiba, n.26, p.75-91, 2006.

BUBER, M.. Do diálogo e do dialógico. São Paulo: Perspectiva, 1982.

BUBER, M.. Eu e Tu. 2 ed. São Paulo: Cortez \& Moraes, 1979.

CAPRA, F.. Alfabetização ecológica. Ipiranga: Editora Cultrix, 2006.

CASCO, A. C. A. J.. Sociedade e Educação Patrimonial. Brasília: IPHAN, 2005.

CASTELL, C. H. G. P.. Metaforizando a vida na terra: um recorte sobre o caráter pedagógico do Teatro-Fórum e sua mediação nos processos de transição agroecológica e cooperação em Rio Grande-RS. Tese (Doutorado) Universidade Federal do Rio Grande do Sul, Porto Alegre, 2007.

CORNELL, J.. Vivências com a natureza 2: novas atividades para pais e educadores. São Paulo: Aquariana, 2008a.

CORNELL, J.. Vivências com a natureza: guia de atividades para pais e educadores. São Paulo: Aquariana, 2008b.

DALONSO, F.. Gestão da Paisagem Cultural Serra Dona Francisca: Possibilidades e Limites. Dissertação (Mestrado em Patrimônio Cultural e Sociedade) - Universidade da Região do Joinville, Joinville, 2016.

DUARTE JUNIOR, J. F.. Itinerário de uma crise: a modernidade. Curitiba: UFPR, 1997.

DUARTE JUNIOR, J. F.. O sentido dos sentidos: a educação (do) sensível. Curitiba: Criar Edições, 2001.

DUARTE, A.. Nova museologia: os pontapés de saída de uma abordagem ainda inovadora. Revista Museologia e Patrimônio, v.6, n.1, p.99-117, 2013.
FAZENDA, I. C. A.. A formação do professor pesquisador: 30 anos de pesquisa. Revista do Grupo de Estudos e Pesquisa em Interdisciplinaridade, São Paulo, v.1, n.1, p. 1-10, 2010

FAZENDA, I. C. A.. Interdisciplinaridade: história, teoria e pesquisa. Campinas: Papirus, 1994.

FAZENDA, I. C. A.. Interdisciplinaridade: um projeto em parceria. São Paulo: Loyola, 1995.

FERRARO JÚNIOR, L. A.; SORRENTINO, M.. Imaginário político e colonialidade: desafios à avaliação qualitativa das políticas públicas de educação ambiental. Ciência \& Educação, v.17, n.2, p.339-352, 2011.

FERRARO JÚNIOR, L.. Encontros e caminhos: formação de educadoras(es) ambientais e coletivos educadores. Brasília: MMA, 2014.

FLORÊNCIO, S. R. R.. Educação Patrimonial: um processo de mediação. In: TOLENTINO, A. B.. Educação Patrimonial: reflexões e práticas. João Pessoa: IPHAN, 2012. p.22-29.

FLUSSER, V.. Elogio à superficialidade: o universo das imagens técnicas. São Paulo: Annablume, 2008.

FLUSSER, V.. Ficções filosóficas. São Paulo: Edusp, 1998.

FREIRE, P.. A pedagogia do oprimido. Rio de Janeiro: Paz e Terra, 1988.

FURIHATA, S. I.; MENDONÇA, R.. O desafio do movimento Sharing Nature na Educação Ambiental contemporânea. Brasília: MMA, 2006.

GALZENARI, M. C.. Práticas de ensino em projeto de educação patrimonial: a produção de saberes educacionais Campinas: Pro-Posições, 2013.

GALZERANI, M. C. B.. A cidade como espaço de aprendizagem da História: em foco um projeto de educação patrimonial. In:

SANTOS, L. L. C. P.. Convergências e tensões no campo da formação do trabalho docente. Belo Horizonte: Autêntica, 2010. p.600-620.

GIL, C. Z. V.; POSSAMAI, Z. R.. Educação patrimonial: percursos, concepções e apropriações. Mouseion, n.19, p.13-26, 2014.

GRUNBERG, E.. Manual de atividades práticas de educação patrimonial. Brasília: IPHAN, 2007.

GUATTARI, F.. As três ecologias. Campinas: Papirus, 1990.

GUATTARI, F.. Caosmose: um novo paradigma estético. São Paulo: Editora 34, 1992.

HALL, S.. Identidade cultural e diáspora. Revista do Patrimônio Histórico e Artístico Nacional, v.24, p.68-76, 1996. 
HALL, S.. Quem precisa da identidade?. In: SILVA, T. T.. Identidade e Diferença: a perspectiva dos estudos culturais. Petrópolis: Vozes, 2000.

HORTA, M. L. P.; GRUNBERG, E.; MONTEIRO, A. Q.. Guia Básico de Educação Patrimonial. Brasília: IPHAN, 1999.

JEUDY, H. P.. Espelho das cidades. Maceió: Casa da Palavra, 2005.

LATOUR, B.. Políticas da natureza: como fazer ciência na democracia. Florianópolis: Edusc, 2004.

LAYRARGUES, P. P.. Identidades da educação ambiental brasileira. Brasília: MMA, 2004.

LE BRETON, D.. Antropologia dos Sentidos. Petrópolis: Vozes. 2016.

LEFF, E.. Complexidade, Interdisciplinaridade e Saber Ambiental. In: PHILLIPI JÚNIOR, A.. Interdisciplinaridade em ciências ambientais. São Paulo: Signus, 2000a.

LEFF, E.. Pensamento sociológico, racionalidade ambiental e transformações do conhecimento. In: LEFF, E..

Epistemologia ambiental. São Paulo: Cortez, 2000b. p.109157.

LITTLE, P. E.. Rumo ao PD/I: análise comparativa e prospectiva dos subprojetos do PD/A. Brasília: Banco Mundial, 1998.

MAFFESOLI, M.. A conquista do presente. Rio de janeiro: Rocco, 1984.

MAFFESOLI, M.. Elogio da razão. Petrópolis: Vozes, 1998.

MAFFESOLI, M.; TEIXEIRA, M. C. S.. A ética pósmoderna. Revista da Faculdade de Educação, v.17, n.1-2, p.194-202, 1991.

MAFFESSOLLI, M.. Socialidade é a marca de ética pósmoderna. São Paulo, 1989.

MELO, C. K.. Educação do Corpomundo: Princípios éticos, estéticos e ecológicos no fortalecimento da sensibilidade humana. In: FALCÃO, J. L. C.; SARAIVA, M. C.. Esporte e lazer na cidade: práticas corporais ressignificadas. Florianópolis: Lagoa Editora, 2007.

MENDONÇA, R.; NEIMAN, Z.. À sombra das árvores: transdisciplinaridade e educação ambiental em atividades extraclasse. São Paulo: Chronos, 2003.

MORAES, M. C.. Educar na biologia do amor e da solidariedade. Petrópolis: Vozes, 2003.

MORAES, M. C.. Paradigma Educacional Emergente. São Paulo: Papirus, 1997.

MORAES, M. C.. Reencantando a educação a partir de novos paradigmas da ciência. São Paulo: PUC, 2004.

MORIN E.. Ciência com consciência. Rio de Janeiro: Bertrand Brasil, 2005.
MORIN E.. Os sete saberes necessários à educação do futuro. São Paulo: Cortez, 2000.

MORIN, E.. A religação dos saberes: o desafio do século XXI. Rio de Janeiro: Bertrand Brasil, 2001.

MOURA, A. C. O. S.. Sensibilização: diferentes olhares na busca dos significados. Dissertação (Mestrado em Educação Ambiental) - Fundação Universidade Federal do Rio Grande, Rio Grande, 2004.

NEIMAN, Z.. A educação ambiental através do contato dirigido com a natureza. Tese (Doutorado), Universidade de São Paulo, São Paulo, 2007.

OLIVEIRA, L.; MACHADO, L. M. C. P.; WANDERLEY, V.; MENESSE, E.. A percepção da paisagem como metodologia de investigação geográfica. In: ENCUENTRO DE GEOGRAFOS DE AMERICA LATINA. Anais. Madrid: AGE, 1989.

PARESCHI, A. C.. Desenvolvimento sustentável e pequenos projetos: entre o projetismo, a ideologia e as dinâmicas sociais. Tese (Doutorado) - Universidade de Brasília, Brasília, 2002.

PELEGRINI, S. C. A.. Cultura e natureza: os desafios das práticas preservacionistas na esfera do patrimônio cultural e ambiental. Revista Brasileira de História, v.26, n.51, p.115140, 2006.

PEREIRA, E. A. T.. O conceito de campo de Pierre Bourdieu: possibilidade de análise para pesquisas em história da educação brasileira. Revista Linhas, v.16, n.32, p.337-356, 2015.

RACHE, R. P.; PATO, C. L.. Arte Educação Ambiental como constructo transdisciplinar. AmbientalMENTE sustentable, v.2, n.20, p.637-656, 2015.

ROCHA, P. E. D.. Arte-educação ambiental como práxis política. In: FÓRUM DE EDUCAÇÃO AMBIENTAL E I ENCONTRO DA REDE BRASILEIRA DE EDUCAÇÃO AMBIENTAL, 4. Anais. Guarapari: REBEA, 1997.

ROCHA, P. E. D.. Arte-educação ambiental para uma cidadania político-participativa. In: ENCONTRO AMBIENTAL VIRTUAL MEIO AMBIENTE. Anais. Hamburgo: Technische Universität Hamburg, 1999.

RODRIGES, L.; ANCIÃES, M.. Verde Perto Educação. Manaus: INPA, 2015.

SANTILLI, J.. Paisagens culturais. Manaus: Instituto Socioambiental, 2016.

SANTOS, B. S.. A crítica da razão indolente: contra o desperdício da experiência. São Paulo: Cortez, 2000.

SANTOS, B. S.. Para uma sociologia das ausências e uma sociologia das emergências. Revista Crítica de Ciências Sociais, Coimbra, n.63, 2002.

SANTOS, B. S.. Um discurso sobre as ciências. São Paulo: Cortez, 2003.

SANTOS, J. E.; JESUS, T. P.; HENKE-OLIVEIRA, C.; BALLESTER, M. V. R.. Caracterização perceptiva da Estação Ecológica de Jataí (Luiz Antônio, SP) por diferentes grupos socioculturais de interação. São Carlos: Rima, 2000. p.163-206. 
SATO, M.. Educação para o ambiente amazônico. Tese (Doutorado em Ecologia e Recursos Naturais) - Universidade Católica de Goiás, Goiás, 1997.

\section{SCHMIDT, A. F.. Trilha da vida e ambientes de} aprendizagem: uma análise na busca de convergências. Dissertação (Mestrado em Educação) - Pontifícia Universidade Católica da São Paulo, São Paulo, 2003.

SCIFONI, S.. A construção do patrimônio natural. Tese (Doutorado em Geografia Humana) - Universidade de São Paulo, São Paulo, 2006.

SILVA, F. W.. Corpo e natureza: perspectivas para uma educação do corpomundo. Dissertação (Mestrado) Universidade Federal de Santa Catarina, Florianópolis, 2007.

SOARES, A. L. R.. De heróis a bandidos: educação patrimonial e ensino de história Ou como manipulamos o passado na construção do presente. In: RAMOS, F. R. L.; LUCAS, M. L.. Tempo no plural: história, memória e diversidade cultural. Fortaleza: Realce, 2008. p.165-178.

SOARES, A. L. R.. Dr. Jeckyl and Mister Hide ou "a educação patrimonial serve a quem?". In: ZANON, E. R.; CASTELO BRANCO, P. M.; MAGALHÃES, L. H.. A construção de políticas patrimoniais: ações preservacionistas de Londrina, Região Norte do Paraná e Sul do país. Londrina: EdUniFil, 2009. p.19-34.

SOARES, A. L. R.. Educação Patrimonial: relatos e experiências. Santa Maria: UFSM, 2003.

SOARES, A. L. R.; KLAMT, S. C.. Educação Patrimonial: teoria e prática. Santa Maria: UFSM, 2007a.
SOARES, A. L. R.; SOUZA, C. S.; CARDÔZO, L.; ALBARELLO, T. H.. A educação patrimonial como instrumento de preservação e democratização da memória e do patrimônio nos Museus. Cadernos do CEOM, n.26, p.109-136, 2007b.

SORRENTINO, M.; NASCIMENTO, E. P.. Universidade e políticas públicas de educação ambiental. Educação em Foco, Barbacena, v.14, n.2, 2010.

SOUZA, I. A. N.. Na confluência da roda: Educação Patrimonial, Diversidade Cultural e a Pedagogia Griô. Brasília: IPHAN, 2014.

SOUZA, S. S.. Corpos movediços, vivências libertárias: a criação de confetos sociopoéticos acerca da autogestão. Tese (Doutorado em Educação Brasileira) - Universidade Federal do Ceará, Fortaleza, 2011.

TEODORO, F.. Trilha da Vida: utilizando Ambiente Virtual de Aprendizagem para Formação à distância em Educação Ambiental. Dissertação (Mestrado em Gestão e Auditoria Ambiental) - Universidad de León, Léon, 2011.

TILDEN, F.. Interpreting our heritage. New York: University of North Carolina Press, 2009.

VARINE-BOHAN, H.. El ecomuseo. Una palabra, dos conceptos, mil prácticas. Revista de los museos de Andalucía, n.8, p.19-29, 2007.

ZANIRATO, S. H.; RIBEIRO, W. C.. Patrimônio cultural: a percepção da natureza como um bem não renovável. Revista Brasileira de História, v.26, n.51, p.251-262, 2006. 